\title{
Impact of Government Regulation on Emission Reduction of Environmental Pollutants in China
}

\author{
Kai Wang* and Xin Yang**† \\ *Admissions and Employment Service Department, Xinyang Normal University, Xinyang, Henan, 464000, China \\ **Social Science Department, Xinyang Normal University, Xinyang, Henan, 464000, China \\ †Corresponding author: Xin Yang; xyangxynu@163.com
}

Nat. Env. \& Poll. Tech.

Website: www.neptjournal.com

Received: 12-05-2021

Revised: $27-07-2021$

Accepted: 21-08-2021

Key Words:

Government regulation

Environmental pollutants

Emission reduction

Panel regression

\begin{abstract}
In pursuit of rapid economic growth, China ignores the carrying capacity of the natural environment and storage quantity of natural resources, resulting in waste and abuse of a large number of natural resources. With the development of industrialization, environmental and ecological problems are becoming more and more serious. Resources are being wasted seriously, and environmental endurance is faced with a great threat. Government regulation on environmental pollution governance has become a consistent problem to be solved for the further economic and social development of all countries in the world. Most governments adopt the establishment of environmental regulation agencies to regulate enterprise pollution. To explore the impact of government regulation on emission reduction of environmental pollutants, government regulation was taken as an explanatory variable and a multivariate panel regression model was established. The influencing factors of environmental pollutant emission in 30 provinces (cities) in China from 2007 to 2016 were estimated. Results show that the government regulation policy in China cannot significantly promote emission reduction of environmental pollutants. GDP and technological progress can effectively reduce the emission of environmental pollutants. The increasing proportion of the secondary industry and a large amount of foreign investment, both lead to an increase in environmental pollutants emission. Government regulation measures can effectively alleviate ecological environment damage caused by environmental pollutant emission. The policy implication of the findings is that the government of China should formulate appropriate intensity of government regulation. The intensity of environmental regulation cannot be blindly increased. Regulation means of pollution charge, pollution permits, and environmental tax should be flexibly used. According to realistic characteristics of different regions, different degrees of excess production capacity, use of government regulation should be different.
\end{abstract}

\section{INTRODUCTION}

Excessive energy consumption and continuous consumption of deteriorating natural resources have led to an increasingly severe ecological environment in China, which has seriously affected the health of urban residents. The extensive development mode characterized by high energy consumption, high pollution, and high output has caused serious environmental pollution in China. Excessive industrial expansion leads to serious excess production capacity. Industries with excess production capacity are mostly highly polluting. Local governments encourage investment at the expense of the environment, and private costs borne by enterprises are far less than social costs, resulting in excessive investment. This ultimately leads to an unbearable burden on resources and the environment. Some developed countries have realized the seriousness of environmental pollution, and have transferred some high-polluting and high-energy-consuming production and processing enterprises to unwary developing countries by means of industrial transfer to gain their biggest economic benefits. Although China is rich in natural resources, due to the transfer of foreign high-pollution enterprises and imperfect production of domestic enterprises, the resources are seriously wasted, and the emission of "three wastes" is gradually increasing, posing a great threat to China's environmental tolerance.

With the progress of technology, development and consumption of environmental resources have caused serious environmental pollution and ecological damage, while many countries and regions have achieved rapid economic growth. With the intensification of the industrialization process, China has achieved rapid economic development while bringing about social problems such as environmental pollution. Environmental pollution is becoming increasingly serious, and the importance of ecological environmental protection is realized. As ecological and environmental problems have seriously affected economic development 
and social stability, the government of China has issued increasingly strict ecological and environmental regulation measures to strengthen environmental constraints to achieve sustainable development. Through the implementation of government regulation, which can be seen as the replacement of market mechanism, the purpose is to maintain good environmental and economic performance. In particular, China has adopted an environmental management system under which governments at all levels are responsible for local environmental quality. The competent environmental protection administrative departments exercise unified supervision and management, and all relevant departments exercise supervision and management in accordance with the law. It has established an environmental management system supplemented by economic incentives such as pollution charges and emission trading systems, which is the most important policy tool for the government to implement environmental regulation. From 2004 to 2019, the Chinese government increased investment in industrial pollution control, with an average annual growth rate of $6.65 \%$, as shown in Fig. 1. As a result, China's sulfur dioxide emissions decreased year by year, with an average annual decline of $5.31 \%$, effectively reducing the emission intensity of environmental pollutants.

\section{EARLIER STUDIES}

As early as the 1970s, economists began to bring regulation into the environment. Environmental pollution governance by government regulation has become an emerging hot field of regulation economics. Local governments are responsible for the implementation and enforcement of government regulation policies on environmental pollution control in China. Government regulation on environmental pollution governance has become a consistent problem to be solved for the further economic and social development of all countries in the world. Most governments in the world adopt the establishment of environmental regulation agencies to regulate enterprise pollution. In terms of government regulation policies in environmental pollution governance, Rothwell (1992) believed that harmful effects of environmental pollution were becoming increasingly obvious and concerned about ozone layer depletion and global warming were increasing, so it was necessary to formulate stricter environmental laws and regulations. Skinner et al. (2003) investigated changing role of local governments in environmental regulation in Zhejiang Province, and results showed that local governments could selectively implement national and provincial policies according to local priorities, which could effectively improve environmental pollution. Beerepoot et al. (2007) focused on the role of stricter government regulations as innovation incentives for the Dutch residential building industry, and the study showed that stricter government regulations and standards contributed to energy technology innovation in Dutch residential buildings. Smith et al. (2008) believed that government environmental regulation could stimulate the application of "clean" technology. Tang et al. (2010) conducted a questionnaire survey of law enforcement officers of the local Environmental Protection Bureau (EPB) in four counties of Guangdong Province of China and found that both local government support and social support would affect local environmental performance. Aronson et al.

3000.00

1200.00

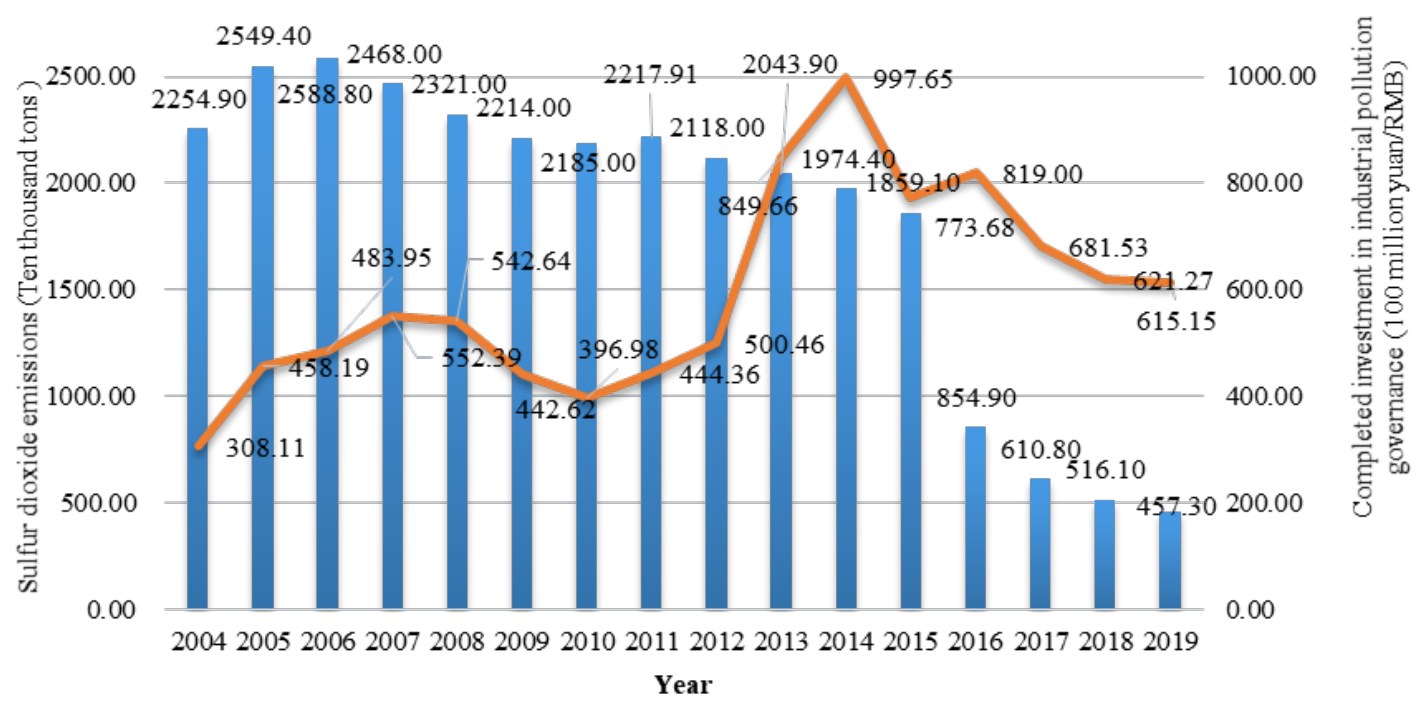

Fig. 1: Sulfur dioxide emissions and completed investment in industrial pollution governance of China from 2004 to 2019. 
(2011) believed that the implementation of strict laws and government regulations could effectively promote successful and large-scale tropical forest restoration. Zhao et al. (2016) showed that government environmental regulation had a significant positive effect on enterprise innovation. Hao et al. (2018) investigated the impact of China's environmental regulations on environmental performance, and results showed that current environmental control measures and regulations didn't achieve the expected goal of pollution control and reduction. Zhou et al. (2019) showed that the pollution supervision effect of local governments in China had been strengthened, and green technological innovation and industrial structure optimization caused by environmental regulation could help alleviate haze pollution. Li et al. (2019) analyzed the relationship between government environmental regulation and regional innovation output, and results showed that environmental regulation had a significant negative effect on regional innovation output, and policy suggestions for strengthening environmental protection were put forward from the perspectives of environmental policy diversity, enterprise innovation incentive and sustainable development concept. Pang et al. (2019) studied the reduction effect of government environmental regulations on emission of environmental pollutants by using panel threshold model, and results highlighted timeliness needed to be considered in evaluating environmental regulation efficiency and emphasized the importance of using differential management. It put forward suggestions of local government enhancing the ability of the environmental protection agency system. Deng et al. (2019) investigated the impact of environmental regulation intensity of local governments on regional innovation performance, and the research showed that improvement of environmental regulation intensity improved regional innovation performance through the innovation compensation effect. Zhang et al. (2019) illustrated how the Chinese government's environmental regulations affected smog pollution control through direct and indirect impacts. Results showed that China's current environmental regulation had effectively suppressed haze pollution and achieved the desired effect. Sheng et al. (2020) theoretically analyzed how environmental regulations of the national government and local government affected enterprises' environmental improvement through the three-party evolutionary game model. Results showed that the environmental regulatory policies of the national government were crucial for realizing the goal of environmental protection. Hamman et al. (2021) discussed how Australian laws at the national government level were applied to the impact of agricultural land on the environment. It could be seen from the existing studies that the nature of public goods of environmental resources made the existence of externality possible. Therefore, it was not feasible to rely on the market mechanism alone, and it would eventually lose control and malfunction. Only the government could add its regulation function. By perfecting government environmental regulation system construction, improving the laws and regulations and policy system, technology innovation, strengthening law enforcement, propaganda and education, and enhancing environmental protection consciousness, China could strengthen ecological environment protection of the government regulation, which could effectively reduce environmental pollutants, and achieve coordinated development of ecological environment and economy.

\section{METHODOLOGY}

The multivariate panel regression model constructed in this study is shown in Formula (1).

$$
\begin{array}{r}
E P O_{i j, t}=\beta_{0}+\beta_{1} G O V_{i j, t}+\beta_{2} G D P_{i j, t}+\beta_{3} T E C_{i j, t}+\beta_{4} S T R_{i j, t} \\
+\beta_{5} F A I_{i j, t}+\varepsilon_{i j, t}
\end{array}
$$

In Formula (1), $E P O_{i j, t}$ represents environmental pollution as the explained variable. Three indicators, industrial wastewater, industrial waste gas, and industrial solid waste discharge ("three industrial wastes"), are selected to measure the comprehensive environmental pollution index, and the average value of the three indicators represents environmental pollutants. Government regulation $\left(G O V_{i j, t}\right)$ represents the explanatory variable. According to Lanoie et al. (2008), the proportion of investment in industrial pollution governance in GDP is used to indicate that the larger the index value is, the greater the intensity of government regulation is. Economic growth $\left(G D P_{i j, t}\right)$ represents the control variable and is represented by the per capita GDP of each region. To eliminate the impact of inflation, the year 2007 is taken as the base period and the value is converted into the actual per capita GDP. Technological innovation level $\left(T E C_{i j, t}\right)$ represents the control variable, which is expressed by the proportion of internal R\&D expenditure in GDP of each region. Industrial structure $\left(S T R_{i j, t}\right)$ represents the control variable and is represented by the proportion of the output value of the secondary industry in GDP. Investment in fixed assets $\left(F A I_{i j, t}\right)$ represents the control variable and is represented by the total investment in fixed assets of the whole society, which is treated by price adjustment. $\mathrm{b}_{0}$ represents the constant term of the regression equation, $\mathrm{b}_{i}=(\mathrm{i}=1,2, \ldots, 5)$ is the coefficient of the regression equation and $\mathrm{e}_{i j, t}$ represents the error term. This study examines 30 provinces (cities) in China (Tibet is not included due to lack of data), with a sample period from 2007 to 2016. The data mainly come from the China Statistical Yearbook, China Environmental Statistics Yearbook, China Demographic Statistics Yearbook and the website of the National Bureau of Statistics. 


\section{RESULTS ANALYSIS}

Panel data regression model usually involves three models, which are mixed (POOL) model, fixed effect (FE) model and random effect (RE) model. Firstly, the F-test is used to select and compare FE model and POOL model. If $p$-value is less than 0.05 , FE model is better. Otherwise, POOL model is used. Secondly, BP test is used to compare the selection of RE model and POOL model. $P$-value is less than 0.05 means that RE model is better. Otherwise, POOL model is used. Thirdly, the Hausman test is used for selecting and comparing FE model and RE model. $P$-value is less than 0.05 means that FE model is better. Otherwise, RE model is used.

As given in Table 1, the panel model involves three models, namely POOL model, FE model and RE model. Firstly, model testing is carried out to find the optimal model. It can be seen from the above table that F-test showed a significance of $5 \% . \mathrm{F}(4,40)=14.224$, and $\mathrm{p}=0.000<0.05$, indicating that FE model is better than POOL model. Hausman test does not show significance. $\operatorname{Chi}(5)=2.165$, and $\mathrm{P}=0.826>0.05$, indicating that RE model is better than FE model. Based on the above analysis, it is suggested to take RE model as the final result, as shown in Table 2.

1. Impact of government regulation on environmental pollution is significantly positive, and it's significant at the level of $5 \%$, indicating simply increasing the intensity of government regulation cannot reduce environmental pollution. The main potential reason is that the Chinese government's investment in environmental pollution governance is less than the GDP growth rate, which

Table 1: Summary of panel model results.

\begin{tabular}{|c|c|c|c|c|c|}
\hline Model Variable & POOL model & FE model & RE model & Time fixed effect & Two-way fixed-effect \\
\hline$c$ & $\begin{array}{l}12.013^{* * *} \\
(9.269)\end{array}$ & $\begin{array}{l}8.507 * * \\
(3.507)\end{array}$ & $\begin{array}{l}10.697 * * \\
(5.581)\end{array}$ & $\begin{array}{l}17.235^{* *} \\
(9.382)\end{array}$ & $\begin{array}{l}4.995^{*} \\
(2.043)\end{array}$ \\
\hline$G O V_{i j, t}$ & $\begin{array}{l}0.140 * * \\
(2.724)\end{array}$ & $\begin{array}{l}0.084^{*} \\
(2.269)\end{array}$ & $\begin{array}{l}0.082 * \\
(2.254)\end{array}$ & $\begin{array}{l}0.019 \\
(0.417)\end{array}$ & $\begin{array}{l}0.041 \\
(1.994)\end{array}$ \\
\hline$G D P_{i j, t}$ & $\begin{array}{l}-0.844 * * \\
(-8.510)\end{array}$ & $\begin{array}{l}-0.152 \\
(-0.500)\end{array}$ & $\begin{array}{l}-0.405 \\
(-1.629)\end{array}$ & $-0.974 * *(-11.722)$ & $\begin{array}{l}0.113 \\
(0.545)\end{array}$ \\
\hline$T E C_{i j, t}$ & $\begin{array}{l}-0.882^{* *} \\
(-2.954)\end{array}$ & $\begin{array}{l}-1.283^{* *} \\
(-3.101)\end{array}$ & $\begin{array}{l}-1.590 * * \\
(-4.593)\end{array}$ & $\begin{array}{l}-0.781 * * \\
(-2.965)\end{array}$ & $\begin{array}{l}-0.202 \\
(-0.747)\end{array}$ \\
\hline$S T R_{i j, t}$ & $\begin{array}{l}0.674 * * \\
(10.554)\end{array}$ & $\begin{array}{l}0.246 \\
(1.062)\end{array}$ & $\begin{array}{l}0.468 * * \\
(2.703)\end{array}$ & $\begin{array}{l}0.495 * * \\
(6.469)\end{array}$ & $-0.037(-0.316)$ \\
\hline$F A I_{i j, t}$ & $\begin{array}{l}-0.106 \\
(-1.961)\end{array}$ & $\begin{array}{l}0.047 \\
(0.807)\end{array}$ & $\begin{array}{l}0.027 \\
(0.491)\end{array}$ & $-0.187 * *(-4.064)$ & $\begin{array}{l}0.019 \\
(0.674)\end{array}$ \\
\hline$R^{2}$ & 0.965 & 0.368 & 0.437 & 0.986 & 0.159 \\
\hline Adjusted $R^{2}$ & 0.961 & 0.226 & 0.373 & 0.98 & -0.329 \\
\hline$N$ & 50 & 50 & 50 & 50 & 50 \\
\hline Test & $\begin{array}{l}F(5,44)=243.117 \\
p=0.000\end{array}$ & $\begin{array}{l}F(5,40)=4.660 \\
p=0.002\end{array}$ & $\begin{array}{l}\chi^{2}(5)=34.115 \\
\mathrm{p}=0.000\end{array}$ & $\begin{array}{l}F(5,35)=485.826 \\
p=0.000\end{array}$ & $\begin{array}{l}F(5,31)=1.174 \\
p=0.344\end{array}$ \\
\hline
\end{tabular}

Note: In Table 1 , * represents $\mathrm{P}<0.05$, ** represents $\mathrm{P}<0.01$, and the corresponding t value is in parentheses.

Table 2: Intermediate process value of RE model.

\begin{tabular}{|lllll|}
\hline Variable & Value & Coefficient & Standard error & $t$ \\
\hline $\mathrm{c}$ & 10.697 & 1.917 & 5.581 & $0.000^{* *}$ \\
$G O V_{i j, t}$ & 0.082 & 0.037 & 2.254 & $0.024 *$ \\
$G D P_{i j, t}$ & -0.405 & 0.248 & -1.629 & 0.103 \\
$T E C_{i j, t}$ & -1.59 & 0.346 & -4.593 & $0.000^{* *}$ \\
$S T R_{i j, t}$ & 0.468 & 0.173 & 2.703 & $0.007 * *$ \\
$F A I_{i j, t}$ & 0.027 & 0.056 & 0.491 & 0.623 \\
\hline
\end{tabular}

$\chi^{2}(5)=34.115, p=0.000, R^{2}=0.437$, Adjusted $R^{2}=0.373$

Note: In Table 2, * represents $P<0.05$, ** represents $P<0.01$ 
cannot effectively alleviate the massive emission of environmental pollutants caused by other factors. The intensity of formal environmental regulations should not be blindly increased. Such regulatory means as pollution charges, pollution permits, and environmental taxes should be flexibly applied, and differentiated intensity of government regulations should be adopted according to actual characteristics of different regions and different levels of overcapacity.

2. Impact of GDP on environmental pollution is significantly negative, but it's not significant. The main reason is that China's GDP has grown too fast in the past 20 years, and the emission of environmental pollutants is affected by the Chinese government's regulations and other factors. The emission of pollutants does not converge with GDP growth and cannot catch up with GDP growth. In particular, with the profound change of the green GDP concept in China, local governments have implemented a new view of achievements. Therefore, environment-friendly characteristics of GDP growth are becoming more and more obvious. Single comprehensive GDP growth will not easily lead to an increase in the emission of environmental pollutants.

3. Impact of technological progress on environmental pollution is significantly negative, and it's significant at the level of $1 \%$, indicating that strengthening technological innovation can indeed reduce the emission of environmental pollutants. It explains that the increase of R\&D of science and technology in the industry promotes the improvement of green technology innovation. The main reason of appearing this kind of situation is that the industrial enterprises of China are in a critical period of traditional economic transformation. Strengthening R\&D of technology can increase innovation of pollution governance technology, to further promote the development of technology innovation.

4. Impact of industrial structure on environmental pollution is significantly positive and it's significant at the level of $1 \%$. It shows that an increasing proportion of the secondary industry will lead to an increase in the emission of environmental pollutants. This shows that when the proportion of the secondary industry increases, the level of environmental pollution will worsen. As the secondary industry is an industry with high energy consumption and high pollution, it mainly includes mining, manufacturing, production and supply of electricity, gas, and water, and construction. Mining and manufacturing them need to consume large amounts of natural energy resources, which is the main source of environmental pollution. Coal energy in the process of combustion will produce large amounts of sulfur dioxide, industrial wastewater and industrial solid waste commonly, and these pollutants in the air, water and ground cause great pollution to the environment.

5. Impact of foreign direct investment on environmental pollution is significantly positive, but it's not significant. It shows that a large amount of foreign investment in China will lead to an increase in environmental pollutant emissions. In the past, to pursue rapid economic development, China had very low environmental requirements for FDI. Developed countries might bring pollution-intensive industries with high pollution and high energy consumption into China, resulting in a large number of pollutant emissions and leading to a large number of pollution-intensive enterprises into China. Due to the requirement of political performance, the incentive of local governments to attract investment and to promote local economy was often greater than that to limit the inflow of foreign investment to protect the environment, which might lead to inflow of polluting foreign direct investment, and the situation that FDI and environmental pollution emissions rose at the same time.

\section{POLICY SUGGESTIONS}

\section{Establishing Reward and Punishment Systems to Strengthen Corporate Awareness of Environmental Responsibility}

The government should formulate rules and regulations, organize leading groups of enterprises to carry out regular lectures and training on environmental protection, cultivate the environmental awareness of enterprises, and promote green production of enterprises. In the rules and regulations, standards should be set, that is, enterprises do not comply with requirements of environmental protection, and they will be severely punished. Under the guidance of the government's environmental regulations, economic growth mode has changed from the original extensive to intensive growth mode, which has achieved a qualitative leap not only in the production mode, but also in the management mode. When the government strengthens the regulation of environmental pollution, on the one hand, the government can provide technical cooperation to ensure strong technical backing. On the other hand, it can provide financial support, such as low-interest loans, financial subsidies, tax breaks and other preferential policies for enterprises engaged in environmental protection research and development technologies. Green products will be produced after environmental pollution governance by enterprises. The government should strictly regulate polluting enterprises and take restrictive measures 
to the non-environmental production of polluting enterprises, to finally reflect the advantages of green products.

\section{Strengthening the Publicity of Green Consumption and Guiding Enterprises to Produce Differentiated Products}

Under the condition of environmental pollution regulation adopted by the government, guiding enterprises to produce differentiated products with environmental protection attributes will greatly improve the regulation effect. Green products with environmental protection attributes may not have competitive advantages after being put into the market, because consumers' awareness of environmental protection attributes of products is different. Therefore, the government should cultivate consumers' awareness of environmental protection and guide the concept of green consumption. Demand for environmental protection products in the market depends on the preferences and requirements of consumers. When the public takes environmental protection as their social mission, they will tend to buy such products with environmental protection attributes. Through policy publicity, news media, and organization of environmental protection activities and other means, the government can enhance consumers' awareness of environmental protection, for environmental protection products opening up sales. Enterprises will pay more attention to environmental protection and promote the sustainable and healthy development of China's economy.

\section{Establishing Incentive Mechanisms for Environmental Pollution Regulators}

In process of environmental pollution regulation, the government also appears as an agent of the public, representing interests of. As a regulator, but also an actor in the economic society, the goal is also to pursue the maximization of interests, resulting in the choice of behavior against the client. Supervision of regulators should be strengthened. It can improve the overall efficiency of regulation through supervision and can grasp more comprehensive and detailed information about polluting enterprises. In terms of system design and concrete implementation of environmental pollution regulation, the department can independently complete system design and concrete implementation, to prevent the inconsistency of each department to affect implementation effect and specific behavior of enterprises. At the same time, on the basis of the establishment of environmental pollution regulation, the establishment of environmental litigation system in the rear can realize differentiation of environmental regulation rights. Through this method, the implementation of the environmental pollution regulation department is supervised. The establishment of environmental litigation institution ensures that the environmental pollution regulation department acts in accordance with the rules, and it supervises them to assume corresponding legal responsibilities once they are found to be improper so that the public's demands can be reasonably resolved.

\section{Improving the Public's Ability to Supervise Polluting Enterprises and Giving Them Economic Rewards}

If the public can join in the supervision of polluting enterprises, it will not only reduce the occurrence of enterprises' pollution behavior, but also greatly enhance environmental awareness. With the enhancement of environmental awareness of the public, constraints on polluting enterprises will be more and more important. Therefore, the environmental pollution regulation department should regularly disclose pollution information of polluting enterprises to the public, and disseminate harm of pollutants to human beings and impact on the living environment of the public through news, newspapers, magazines and other social media. In process of environmental pollution regulation by the government, many small and medium-sized enterprises violate the rules of emission. The purpose of regulating environmental pollution of small and medium-sized enterprises is not to rule them out of the market, but to regulate their pollution behavior. However, for most small and medium-sized enterprises, high regulatory costs often become an important obstacle to restrict production. In this regard, the government should formulate corresponding policies to provide economic compensation and technical support to them.

\section{CONCLUSION}

The extensive development mode characterized by high energy consumption, high pollution and high output has caused serious environmental pollution in China. Government regulation policy is an effective means to realize China's economic transformation and upgrading, to solve environmental pollution problems and to improve environmental performance. To test the impact of government regulation on environmental pollution, government regulation as an explanatory variable was included and a multiple panel regression model was established. The influencing factors of environmental pollutant emission in 30 provinces (cities) in China from 2007 to 2016 were estimated. Conclusions can be drawn that: (1) Government regulation policy in China cannot significantly promote emission reduction of environmental pollutants. (2) GDP and technological progress can effectively reduce emissions of environmental pollutants. (3) Increase in the proportion of the secondary industry and the introduction of large amounts of foreign investment leads to an increase in environmental pollutant emission. 
Finally, it puts forward policy suggestions, including constructing rewards and punishment system to strengthen environment responsibility consciousness of enterprises, enhancing the promotion of green consumption to guide the enterprise to produce differentiated products, establishing incentive mechanism for regulators of environmental pollution, improving the ability of the public to supervise polluting enterprises. Those government regulation measures can mitigate ecological environmental damage caused by environmental pollutants. It suggests that further research should be carried out on setting of environmental pollution regulation standards, the impact of environmental information disclosure on pollutant emission, and establishment of green technology innovation mechanism of enterprises.

\section{REFERENCES}

Aronson, J., Brancalion, P. H., Durigan, G., Rodrigues, R. R., Engel, V. L., Tabarelli, M. and Scarano, F. R. 2011. What Role Should Government Regulation Play in Ecological Restoration? Ongoing Debate in São Paulo State, Brazil. Restoration Ecology, 19(6): 690-695.

Beerepoot, M. and Beerepoot, N. 2007. Government Regulation as an Impetus for Innovation: Evidence from Energy Performance Regulation in the Dutch Residential Building Sector. Energy Policy, 35(10): 4812-4825.

Deng, J., Zhang, N., Ahmad, F. and Draz, M. U. 2019. Local Government Competition, Environmental Regulation Intensity and Regional Innovation Performance: An Empirical Investigation of Chinese Provinces. International Journal of Environmental Research and Public Health, 16(12): 2130.

Hamman, E., Deane, F., Kennedy, A., Huggins, A. and Nay, Z. 2021. Environmental Regulation of Agriculture in Federal Systems of Government: The Case of Australia. Agronomy, 11(8): 1478.

Hao, Y., Deng, Y., Lu, Z. N. and Chen, H. 2018. Is Environmental Regulation Effective in China? Evidence from City-level Panel Data. Journal of Cleaner Production, 188: 966-976.
Lanoie, P., Patry, M. and Lajeunesse, R. 2008. Environmental Regulation and Productivity: Testing the Porter Hypothesis. Journal of Productivity Analysis, 30(2): 121-128.

Li, Y., Tang, Y., Wang, K. and Zhao, Q. 2019. Environmental Regulation and China's Regional Innovation Output: Empirical Research Based on Spatial Durbin Model. Sustainability, 11(20): 5602.

Pang, R., Zheng, D., Shi, M. and Zhang, X. 2019. Pollute First, Control Later? Exploring the Economic Threshold of Effective Environmental Regulation in China's Context. Journal of Environmental Management, 248: 109275 .

Rothwell, R. 1992. Industrial Innovation and Government Environmental Regulation: Some Lessons from the Past. Technovation, 12(7): 447-458.

Sheng, J., Zhou, W. and Zhu, B. 2020. The Coordination of Stakeholder Interests in Environmental Regulation: Lessons from China's Environmental Regulation Policies from the Perspective of the Evolutionary Game Theory. Journal of Cleaner Production, 249: 119385.

Skinner, M. W., Joseph, A. E. and Kuhn, R. G. 2003. Social and Environmental Regulation in Rural China: Bringing the Changing Role of Local Government into Focus. Geoforum, 34(2): 267-281.

Smith, M. and Crotty, J. 2008. Environmental Regulation and Innovation Driving Ecological Design in the UK Automotive Industry. Business Strategy and the Environment, 17(6): 341-349.

Tang, S. Y., Lo, W. H. and Fryxell, G. E. 2010. Governance Reform, External Support, and Environmental Regulation Enforcement in Rural China: The Case of Guangdong Province. Journal of Environmental Management, 91(10): 2008-2018.

Zhang, M., Liu, X., Ding, Y. and Wang, W. 2019. How Does Environmental Regulation Affect Haze Pollution Governance? An Empirical Test based on Chinese Provincial Panel Data. Science of the Total Environment, 695: 133905.

Zhao, X. and Sun, B. 2015. The Influence of Chinese Environmental Regulation on Corporation Innovation and Competitiveness. Journal of Cleaner Production, 112: 1528-1536.

Zhou, Q., Zhang, X., Shao, Q. and Wang, X. 2019. The Non-linear Effect of Environmental Regulation on Haze Pollution: Empirical Evidence for 277 Chinese Cities during 2002-2010. Journal of Environmental Management, 248: 109274. 